\title{
MOTIF UKIRAN KERAWANG GAYO PADA RUMAH ADAT GAYO DI KABUPATEN ACEH TENGAH PROVINSI ACEH
}

\author{
Ansar Salihin $^{1^{*}}$, Sulaiman Juned ${ }^{2 *}$, Dharsono ${ }^{3 *}$ \\ Program Pascasarjana \\ Institut Seni Indonesia Padangpanjang \\ Jl. Bahder Johan, Guguak Malintang, Padangpanjang, Kota Padangpanjang, 27126. \\ Sumatera Barat. Indonesia \\ Email:weinansar@gmail.com
}

\begin{abstract}
Abstrak
Kerawang Gayo merupakan hiasan berupa motif ukir atau ragam hias yang diterapkan pada rumah adat Gayo di Kabupaten Aceh Tengah. Motif kerawang diciptakan oleh masyarakat Gayo melalui proses daya fikir secara spontanitas, kemudian direnungkan secara mendalam sehingga melahirkan suatu bentuk motif yang memiliki makna filosofis berkaitan dengan kehidupan masyarakat Gayo. Tujuan penelitian ini untuk menjelaskan latar belakang munculnya motif kerawang Gayo dan menjelaskan bentuk serta pemaknaanya motif kerawang Gayo pada rumah adat Gayo. Kerangka untuk mengkaji bentuk dan makna motif kerawang Gayo menggunakan teori estetika tentang motif yang dibagi tiga yaitu motif utama (wujud tertentu, memiliki falsafah atau ajaran), kemudin motif pengisi (pendukung motif utama) dan motif isian (penghias motif utama dan pendukung). Jenis penelitian ini kualitatif pendekatan terhadap kultural masyarakat Gayo, dengan teknik pencarian data studi pustaka, observasi, wawancara, dokumentasi dan studi karya/artefak. Berdasarkan hasil penelitian dan teori estetika tersebut menemukan tiga belas bentuk motif ukiran yang terdapat pada rumah adat Gayo, masing-masing memiliki filosofi dalam bentuk peri mestike (Falsafah/Pribahasa) yang mengandung ajaran atau tuntunan berkaitan dengan kehidupan masyarakat Gayo. Motif ukiran kerawang Gayo pada rumah adat Gayo diantaranya emun berangkat (awan berarak), emun beriring (awan berbaris) emun berkune (awan bercabang) emun mupesir (awan berpencar) emun mutumpuk (awan berkumpul) puter tali (pilin berganda) pucuk rebun (pucuk rebung) tekukur (pengukuran) mata ni lo (matahari) sarak opat (sarak empat) nege (naga) iken (ikan) dan kurik (ayam).
\end{abstract}

Kata Kunci: rumah adat, kerawang gayo, estetika.

\begin{abstract}
Kerawang Gayo is an ornament in the form of a carved motif or decoration applied to the Gayo traditional house in Central Aceh Regency. Kerawang motifs created by the Gayo community through spontaneous processes of thinking power, then contemplated in depth so as to give birth to a form of motif that has philosophical meaning related to the life of the Gayo people. The purpose of this study is to explain the background of the emergence of the motif kerawang Gayo and explain the shape and meaning of the motif kerawang Gayo on the Gayo traditional house. The framework for examining the form and meaning of the Gayo openwork motif uses aesthetic theories about motives divided into three, namely the main motifs (certain forms, philosophies or teachings), then the motives of fillers (supporting the main motifs) and stuffing motifs (decorating the main and supporting motifs). This research is a qualitative approach to the culture of the Gayo community, with techniques for finding data from literature studies, observations, interviews, documentation and study works/artifacts. Based on the results of the research and aesthetic theory found thirteen forms of carving motifs found in the Gayo traditional house, each of them has a philosophy in the form of peri mestike (Philosophy/Language) which contains teachings or guidance relating to the lives of the Gayo people. The motif kerawang Gayo on the Gayo traditional house includes emun berangkat (cloud drifting), emun beriring (cloud lining) emun berkune (branching cloud) emun mupesir (scattered cloud) emun mutumpuk (cloud gathered) puter tali (multiple gyre) pucuk rebun (shoots bamboo shoots) tekukur (measurement) mata ni lo (sun) sarak opat (four sarak) nege (dragon) iken (fish) and kurik (rooster).
\end{abstract}

Keywords: traditional house, kerrawang gayo, aesthetics. 


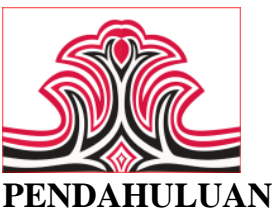

Kerawang merupakan hiasan dalam bentuk motif atau ragam hias yang terletak pada suatu benda seperti bangunan, pakaian dan gerabah. Kerawang atau sering disebut kerawang Gayo adalah salah satu karya seni rupa tradisi masyarakat Gayo di kabupaten Aceh Tengah Provinsi Aceh. Produk budaya ini adalah salah satu identitas masyarakat Gayo yang masih dipelihara sampai saat ini.

Kerawang berasal dari kata "ker" dan "rawang". Ker dalam bahasa Gayo bermakna daya fikir dan rancangan yang abstrak terjadi spontan. Kemudian rawang yang berarti ramal atau bayangan bisa dari fenomena alam, proses terjadinya sudah berdasarkan pikiran. Jadi, kerawang merupakan wujud dari imajinasi spontanitas individu manusianya (Joni, 2017: 37).

Pemahaman secara umum kerawang diartikan ukiran atau bordiran yang berlubang. Pengertian ini tidak asing lagi di kalangan masyarakat di Indonesia. Sementara pengertian kerawang dalam masyarakat Gayo bukan ukiran tembus atau bordiran tembus, melainkan nama motif ukir atau ragam hias yang diterapkan pada suatu benda atau media.

Kerawang Gayo menurut Ibrahim (2002: 180) adalah: "Alam hewani (fauna) dan alam tumbuh-tumbuhan (flora) menunjukkan dirinya kepada manusia Gayo untuk menemukan motif-motif ukir yang disebut kerawang Gayo. Motif-motif itu dinukil pada bahanbahan yang ada di sekitar mereka yaitu pada kayu bangunan, tanah liat menghasilkan keramik, bahan anyaman, tenunan kain dan logam”.

Motif kerawang Gayo bersumber dari penggambaran tumbuhan, hewan dan alam di daerah Gayo, melalui penggambaran itulah memberikan dorongan kepada masyarakat Gayo untuk mewujudkan karya berupa motif ukir diterapkan pada bangunan. Salah satu motif kerawang Gayo tertua dalam bentuk ukiran kayu terletak pada rumah adat Gayo.

Rumah adat Gayo atau sering juga disebut umah pitu ruang (Rumah tujuh ruang) berbentuk rumah panggung arsitektur tradisional. Rumah adat Gayo berfungsi sebagai tempat pelaksanaan upacara adat atau kegiatan adat dan budaya. Selain itu rumah adat Gayo merupakan tempat tinggal raja atau istana kerajaan

Rumah adat adalah komponen penting dari unsur fisik yang mencerminkan kesatuan sakral dan kesatuan sosial. Pembangunan dilaksanakan secara gotong
Gorga Jurnal Seni Rupa

Volume 08 Nomor 01 Januari-Juni 2019

p-ISSN: 2301-5942 | e-ISSN: 2580-2380

royong. Dalam membangun rumah adat mempunyai tatacara dengan melaksanakan serangkaian upacara kegiatan yang berupa religius (Tamraz, 1996: 4).

Rumah adat Gayo yang ada di Aceh Tengah diantaranya umah pitu ruang reje Baluntara di Desa Toweren, umah pitu ruang musiem reje Linge di Desa Linge, umah pitu ruang di Museum Negeri Antara Takengon, dan anjungan umah pitu ruang Aceh Tengah di Taman Ratu Safiatuddin Banda Aceh.

Berdasarkan empat rumah adat tersebut yang masih asli adalah umah pitu ruang kerajaan Baluntara di Toweren. Sementara rumah adat lainnya seperti rumah adat Gayo di Linge sudah mengalami renovasi dari bentuk aslinya setelah terbakar sebelumnya. Sementara rumah adat Gayo di museum Negeri Antara dan Anjungan rumah adat Gayo di Taman Ratu Safiatuddin Banda Aceh merupakan rumah adat Gayo yang baru dibangun oleh pemerintah daerah untuk melestarikan produk budaya Gayo.

Saat ini terdapat satu rumah tinggal tradisional suku Gayo Laut yang masih bertahan di sekitar kota Takengon. Rumah tinggal tradisional tersebut berada di kampung Toweren tepat di sisi danau Laut Tawar. Fasad dan denah rumah tradisional ini masih mempertahankan bentuk aslinya walaupun dengan kondisi yang kian hancur (Sylviana, 2015: 41).

Motif ukiran kerawang Gayo pada rumah adat Gayo di Aceh Tengah tertarik untuk diteliti dan dikaji secara ilmiah karena motif kerawang rumah adat Gayo merupakan hasil karya seni tradisi masyarakat Gayo. Motif kerawang Gayo selain sebagai hiasan untuk keindahan juga sebagai pengingat, penyampaian pesan moral dan mengandung ajaran dalam kehidupan masyarakat Gayo. Setiap motif memiliki bentuk dan pemaknaan yang harus dikaji secara mendalam, melalui hasil penelitian ini mengungkap makna-makna motif tersebut.

Penelitian tentang motif kerawang Gayo telah pernah dilakukan sebelumnya oleh peneliti baik dalam bentuk tesis maupun buku. Hasil penelitian atau referensi itu dapat menjadi perbandingan untuk menjaga orisinalitas kajian ini. Penelitian Ferawati (2010) Pascasarjana ISI Padangpanjang "Motif Kerawang Gayo Busana Adat Pengantin Gayo Aceh Tengah" Hasil penelitian membahas tentang pakaian adat pernikahan masyarakat Gayo, motif kerawang Gayo yang diterapakn pada pakaian adat pernikahan baik secara bentuk dan maknanya. Kemudin penelitian Sylviana Mirahayu Irfani (2015) Fakultas Teknik Universitas Sumatera Utara "Kajian Arsitektur 


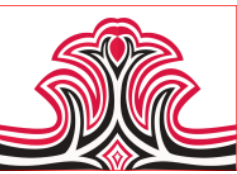

Tradisional Sebagai Acuan Desain Rumah Tinggal Kontemporer (Studi Kasus: Arsitektur Vernakular Gayo Lut di Kota Takengon)" Membahas tentang arsitektur tradisional, perubahan bentuk rumah tinggal masyarakat Gayo dari masa ke masa dan acuan desain untuk bangunan rumah modern yang bersumber dari rumah tradisional Gayo. Kemudian penelitian Joni, Bentara Linge, Dkk (2017) “Kerawang Gayo". Buku tersebut merupakan hasil penelitian dan seminar kerawang Gayo, membahas tentang fenomena kerawang Gayo, asal usul kerawang Gayo, filosofi motif kerawang Gayo, dan penempatan pemakaian kerawang gayo pada pakaian menurut adat.

Penelitian motif ukiran kerawang Gayo pada rumah adat Gayo di Aceh Tengah bertujuan menjelaskan hiasan motif ukiran kerawang Gayo pada rumah adat Gayo di Aceh Tengah. Kemudin menjelaskan secara estetik bentuk dan pemaknaannya motif kerawang Gayo pada rumah adat Gayo di Aceh Tengah.

\section{KAJIAN TEORI}

Kajian teori merupakan kerangka konseptual atau teori yang digunakan dalam pola pikir untuk mencapai tujuan penelitian, melalui kajian teori mengkaji secara mendalam objek material. Penelitian ini menggunakan kajian teori estetika stuktural (secara tersturktur) untuk mengkaji dan menganalisis bentuk dan pemaknaanya motif ukiran kerawang Gayo pada rumah adat Gayo di Aceh Tengah.

Estetika berasal dari bahasa Yunani aisthetikos yang secara harfiah berarti memahami melalui pengamatan indrawi, kata yang dalam bahasa Inggris ditulis aesthethics atau kadang esthetics itu memiliki akar kata aisthesis yang berarti perasaan maupun persepsi. Secara maknawi definisi estetika sebagai kajian tentang proses yang terjadi antara subjek, objek, dan nilai yang terkait dengan pengalaman, properti, dan parameter kemenarikan maupun ketidakmenarikan (Junaedi, 2016: 14).

Sementara Martin (2016:3) Estetika adalah filsafat kesenian. Estetika tidak hanya membahas nilai estetis, tetapi juga pengalaman estetis, status ontologis karya seni dan hubungan seni dengan masyarakat. Kemudian Dharsono (2004:5) menjelaskan, estetika diartikan sebagai suatu cabang filsafat yang memperhatikan atau berhubungan dengan gejala yang indah pada alam dan seni.

"Bentuk adalah struktur atau komposisi, merupakan tata susun yang terdiri dari pengulangan atau susunan pola. Pola terdiri dari motif utama, motif pengisi (selingan), dan motif isian. (1) Motif utama,
Gorga Jurnal Seni Rupa

Volume 08 Nomor 01 Januari-Juni 2019

p-ISSN: 2301-5942 | e-ISSN: 2580-2380

merupakan unsur pokok berupa gambar-gambar dari wujud tertentu. Motif utama karena merupakan unsur (elemen) pokok maka sering disebut ornamen pokok (ornamen utama). Pada kesenian klasik, motif utama merupakan motif yang mengandung falsafah atau ajaran (tuntunan). (2) Motif pengisi (motif selingan) merupakan unsur pendukung, berupa gambar-gambar dari bentuk tertentu, dibuat untuk mengisi bidang diantara motif utama atau diantara pola batik. Biasanya dibuat lebih kecil dari motif utama, fungsinya untuk melengkapi tata susun dalam pembuatan pola. Motif pengisi karena dianggap sebagai unsur pendukung, maka biasa disebut motif pendukung atau ornamen pengisi (selingan). Fungsinya sebagai penghias pola (3) Isen (isian), merupakan unsur pengisi yang fungsinya menghias motif utama maupun motif selingan (pendukung). Motif ini pada seni rupa biasanya berupa titik-titik, garis-garis, gabungan titik, garis (dalam tari-variasi gerak)". (Dharsono, 2016: 77-78).

Berdasarkan teori estetika tersebut menjelaskan ada tiga pola motif yaitu motif utama, selingan dan isian. Ketiga jenis motif tersebut menyatu dalam satu kesatuan pada ornamen atau ragam hias yang diterapkan pada suatu media. Begitu halnya dengan motif ukiran kerawang Gayo pada rumah adat Gayo mempunyai tiga pola motif, motif utama yang merupakan motif yang memiliki bentuk tertentu dan memiliki nilai filosofis atau pesan ajaran. Kemudian motif selingan untuk menghias motif utama ukiran kerawang Gayo. Dan motif isian berupa titik dan garis yang menghias motif utama dan motif selingan ukiran kerawang Gayo pada rumah adat Gayo. Teori estetika ini digunakan sebagai kerangka teoritis atau konsep pola fikir peneliti untuk mengkaji dan menganalisis bentuk dan pemaknaannya motif ukiran kerawang Gayo pada rumah adat Gayo.

\section{METODE PENELITIAN}

\section{Jenis Penelitian}

Penelitian untuk mengkaji motif ukiran kerawang Gayo pada rumah adat Gayo menggunakan jenis penelitian kualitatif, karena dipandang objek penelitian ini lebih mendekati cultural dalam masyarakat. Tujuannya untuk mendalami dan memperoleh kualitas dari objek penelitian dengan berbagai pendekatan disiplin ilmu.

Penelitian seni secara kualitatif merupakan penelitian untuk menangkap data tentang seni dan persepsi dari para pelaku setempat dengan pandangan dari dalam melalui proses perhatian dan pemahaman mendalam. Tugas utama peneliti seni dalam penelitian kualitatif 


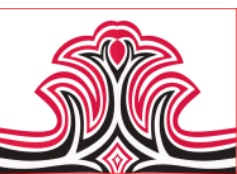

adalah menjelaskan secara teliti cara-cara orang yang berada dalam latar tertentu, karya-karya atau dari hasil tindakan, sehingga dapat memahami, memperkirakan, mengambil langkah-langkah yang diperlukan (Tjetjep, 2011: 47-48).

\section{Lokasi Penelitian}

Penelitian ini dilaksanakan di empat tempat diantaranya rumah adat Gayo kerajaan baluntara di Desa Toweren Kecamatan Laut Tawar Kabupaten Aceh Tengah, rumah adat Gayo Museum Kerajaan Linge di Desa Linge Kecamatan Linge Kabupaten Aceh Tengah, Rumah adat Gayo Museum Negeri Antara di Desa Kemili Kecamatan Kebayakan Kabupaten Aceh Tengah, dan anjungan rumah adat Gayo Aceh Tengah di Taman Ratu Safiatuddun Banda Aceh, Provinsi Aceh. Pemilihan lokasi tersebut dengan alasan objek utama penelitian ini rumah adat Gayo Aceh Tengah berada di daerah tersebut.

\section{Sumber Data}

Sumber data merupakan sumber informasi yang diperoleh selama penelitian. Sumber tersebut didapatkan dengan berbagai cara untuk memperoleh data yang akurat, seperti sumber data secara langsung maupun data tidak langsung. Sumber data ini kemudian diolah dengan menganalisis berdasarkan teori yang digunakan. Sumber data dalam penelitian ini terbagi empat yaitu data karya/artefak (motif ukiran kerawang Gayo), data dari narasumber berdasarkan hasil wawancara, data pustaka berupa buku, jurnal dan tesis, dan dokumen atau arsip yang berhubungan dengan motif ukiran kerawang Gayo.

\section{Teknik Pengumpulan Data 1).Studi Pustaka}

Studi pustaka merupakan pengumpulan data awal dengan cara mencari, membaca dan mereview data berhubungan dengan motif ukiran kerawang Gayo. Studi pustaka bertujuan untuk mendapatkan data tertulis dari sumber pustaka seperti tesis, desertasi, laporan ilmiah, jurnal, buku dan sumber lainnya yang dianggap akurat dan terpercaya.

\section{2).Observasi}

Observasi motif ukiran kerawang Gayo dilakukan secara langsung di rumah adat Gayo di Kabupaten Aceh. Tahapan observasi dimulai mencari informasi keberadaan motif ukiran kerawang Gayo rumah adat Gayo, kemudian mengunjungi objek penelitian, dilanjutkan mengamati motif ukiran kerawang pada rumah adat Gayo. Pengambilan rekaman foto bentuk motif secara global dan bentuk motif satu-persatu. Mencatat seluruh hasil pengamatan yang dilakukan di lapangan.
Gorga Jurnal Seni Rupa

Volume 08 Nomor 01 Januari-Juni 2019

p-ISSN: 2301-5942 | e-ISSN: 2580-2380

\section{3).Wawancara}

Peneliti mengumpulkan data dengan mewawancarai tokoh intelektual, budayawan Gayo, akademisi, penjaga atau pewaris rumah adat Gayo dan pembuat rumah adat Gayo di Aceh Tengah. Wawancara dibantu dengan alat perekam audio dan video untuk memastikan keakuratan data yang disampaikan oleh informan. Hasil wawancara memperoleh data yang belum terjawab pada saat observasi.

\section{4).Dokumentasi}

Teknik dokumentasi adalah pencarian data berdasarkan dokumen-dokumen atau arsip yang disimpan oleh orang-orang tertentu atau museum yang berkaintan dengan objek penelitian motif ukiran kerawang pada rumah adat Gayo. Dokumen ini baik berbentuk tulisan, foto, desain dan bentuk lainnya yang masih tersimpan sampai sekarang. Dokumendokumen tersebut kemudian dikaji dan dianalisis untuk mengsingkronkan data dengan hasil observasi dan wawancara.

\section{5).Studi Karya/ Artefak}

Studi karya/artefak teknik pengumpulan data dengan cara melakukan pengamatan dan pengkajian terhadap motif ukiran kerawang Gayo pada rumah adat Gayo. Studi karya ini memilah dan mengelompokan bentuk motif ukiran kerawang Gayo berdasarkan jenis dan peletakannya pada rumah adat Gayo. Selanjutnya dalam studi karya juga membuat ulang desain motif ukiran kerawang Gayo untuk melahirkan suatu pola motif kerawang Gayo. Hasil dari studi karya ini adalah menemukan bentuk-bentuk motif ukiran kerawang Gayo dan desain pola motif kerawang Gayo pada rumah adat Gayo di Aceh Tengah.

\section{Analisis Data}

Analisis data seni adalah suatu cara bagi pencarian atau pengujian pernyataan umum tentang keterkaitan dan yang mendasari tema-tema yang membangun teori dari lapangan. Analisis bukanlah semata-mata persoalan tentang melekatkan suatu kegiatan pada pendekatan atau seperangkat teknik yang benar, analisis dalam penelitian seni lebih bersifat imajinatif (Tjetjep, 2011: 222-223).

Data hasil studi pustaka, hasil obervasi, hasil wawancara, dokumentasi dan studi karya divalidasi kebenarannya. Selanjutnya memetakan dan mengelompokan motif ukiran kerawang Gayo berdasarkan jenis motif dan peletakannya pada rumah adat Gayo. Kemudian mengkaji bentuk motif ukiran kerawang Gayo mulai dari nama motif, bentuk pola desain dan penerapan motif ukiran pada rumah adat Gayo. Selanjutnya menganalisis dan menginterpretasi 


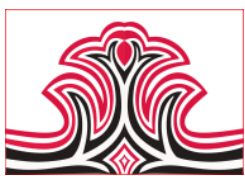

pemaknaan motif kerawang Gayo pada rumah adat Gayo menggunakan kerangka teori estetika.

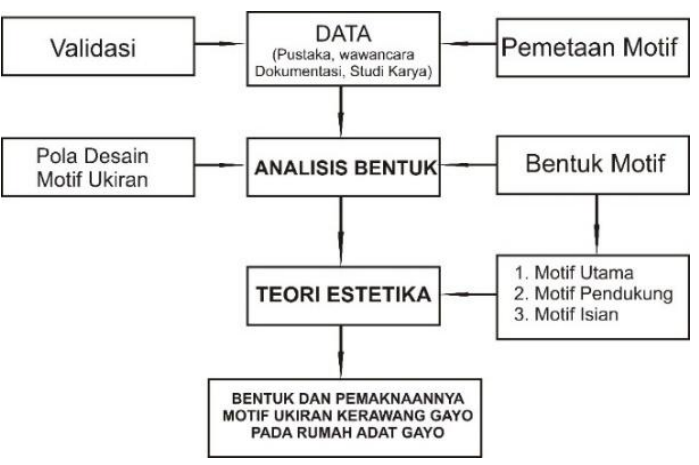

Gambar 1. Analisis Motif Ukiran Kerawang Gayo pada Rumah Adat Gayo

(Sumber: Ansar Salihin, 2018)

Hasil dari analisis adalah mampu menjawab seluruh permasalahan objek penelitian, yaitu estetika motif ukiran kerawang Gayo pada rumah adat Gayo dan bentuk dan pemaknaannya motif ukiran kerawang Gayo pada rumah adat Gayo. Berdasarkan hasil analisis ini menemukan kesimpulan bahwa motif ukiran kerawang Gayo pada rumah adat Gayo memiliki nilai estetika.

\section{HASIL DAN PEMBAHASAN}

\section{Hasil}

Suku Gayo adalah salah satu bagian dari suku yang ada di bumi pertiwi Republik Indonesia yang mendiami Dataran Tinggi Tanah Gayo di Kabupaten Aceh Tengah, Bener Meriah, Aceh Tenggara, Gayo Lues, Pulo Tige, Lokop Serbejadi, dan tersebar ke daerah lainnya (Joni, 2017: 16).

Sementara menurut Mahmud Ibrahim, Suku Gayo adalah berasal dari Malayu tua yang datang ke Sumatera gelombang pertama dan menetap di pantai utara dan timur Aceh serta sepanjang aliran sungai Jambo Aye, sungai Perlak dan sungai Tamiang. Kemudian menyusur daerah aliran sungai itu berkembang ke Serbejadi Linge dan Gayo Lues (2007: 5).

Seiring bertambahnya penduduk dan mulai menyebar dari daerah Linge. Kerajaan Linge membagi wilayah menjadi empat kerajaan masing-masing memiliki raja sendiri dan memperluas wilayah kerajaan yang ada di Gayo. Kerajaan tersebut ialah Syiah Utama, Bukit dan Petiamang serta Linge sebagai pusat kerajaan.

Sejarah kerajaan di Gayo ada empat kerajaan, itu tertuang dalam pepatah "siopat mukawalen, sipitu mudenie” Artinya: Yang empat mempunyai wilayah,
Gorga Jurnal Seni Rupa

Volume 08 Nomor 01 Januari-Juni 2019

p-ISSN: 2301-5942 | e-ISSN: 2580-2380

yang tujuh mempunyai dunia. Yang empat diantaranya, pertama reje Linge di Buntul Linge, kedua reje Syiah Utama di Nosar, ketiga reje bukit di Kebayakan dan keempat reje petiamang di Blang Kejeren Gayo Lues. Sementara Kerajaan Baluntara adalah pecahan dari kerajaan Bukit yang berada di Toweren. Kerajaan Bukit memerintahkan kepada anaknya untuk mendirikan sebuah kerajaan diberi nama Baluntara atau Belantara yaitu kerajaan yang menguasai wilayah hutan belantara yang ada di sekitarnya (Wawancara, Syeh Samsudin, 2016).

Setiap kerajaan di Gayo memiliki istana kerajaan sebagai tempat tinggal raja, tempat musyawarah dan tempat pelaksanaan upacara adat. Ada kerajaan yang masih meninggalkan rumah adat seperti kerajaan Baluntara yang bentuknya masih asli, sementara kerajaan Linge rumah adatnya sudah mengalami perubahan setelah terbakar dua kali sebelumnya, kerajaan Bukit tidak ada lagi memiliki rumah adat, namun di Bangun di Kebayakan umah pitu ruang oleh Pemerintah sebagai Museum, sementara Kerajaan Syiah Utama sama sekali tidak ada lagi rumah adatnya setelah mengalami kepunahan beberapa tahun yang lalu.

\section{1).Rumah Adat Gayo}

Umah pitu ruang (rumah tujuh ruang) merupakan rumah adat Gayo yang dibangun berdasarkan edet urum ukum (adat dan hukum). Edet ditetapkan melalui sarak opat (musyawarah), hukum berdasarkan agama. Pada zaman dahulu rumah tersebut ditempati oleh reje (raja). Fungsinya sebagai istana kerajaan, tempat bermusyawarah dan pelaksanaan acara adat lainnya (wawancara: Abdussalam: 2 Januari 2017).

Umah pitu ruang mengandung unsur nomorik angka pitu atau tujuh. Tentunya angka tujuh ini memiliki dasar filosofi yang kaitannya berhubungan dengan adat Gayo. Bagi masyarakat Gayo angka pitu ini mempunyai nilai sakral mengandung filosofi dalam kehidupan manusia.

Filosofi angka tujuh dalam masyarakat Gayo "kulangit bintang pitu, kubumi kal pitu kala" Induk dari ku langit bintang pitu (ke langit bintang tujuh) adalah tujuh anggota tubuh dalam menghadap tuhan dan induk ku bumi kal pitu mata (ke bumi kal/takaran tujuh mata) adalah enam rukun iman ditambah satu adat. Gabungan keduanya menjadi tujuh dasar mengatur kehidupan manusia yaitu ayat, sabda, kiyes (kiyas), ijma', inget (Ingat), resam, atur (aturan). Filosofi inilah yang diterapkan dalam rumah adat Gayo umah pitu ruang (Wawancara: Joni, 12 Agustus 2018). 


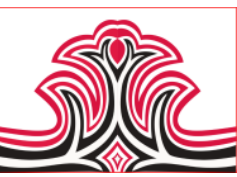

Kata adat "i atas bintang tujuh, i tuyuh kal pitu mata" merupakan semboyan reje Linge yang diterapkan pada umah pitu ruang sebagai rumah adat Gayo. "iatas bintang tujuh" merupakan hubungan vertikal langsung manusia dengan khalik, sedangkan "ituyuh kal pitu mata" merupakan hubungan horizontal manusia sesama manusia. Penerapannya dalam rumah adat Gayo tujuh komponen di bagian atas yaitu: bere bujur, bere lintang, tunyuk diri, tulen bubung, kaso gantong, kaso, dan tutupen kaso. Sedangkan tujuh komponen rumah adat di bagian bawah yaitu: Tailen, Gergel, Tumuk, Tupang, tupang, pasak, pating dan baji. (Wawancara: Bentara, 12 Agustus 2018).

Kedua pendapat di atas menegaskan makna dan filosofi angka pitu atau tujuh menurut pandangan masyarakat Gayo. Filosofi tujuh anggota tubuh dalam ibadah kepada Allah diperkuat dengan mempercayai rukun iman ditambah menjalankan peraturan adat. Filosofi itu juga diterapkan dalam rumah adat Gayo tujuh komponen yang kontruksikan pada bagian atas rumah adat Gayo agar kokoh pada bagian atap dan tujuh komponen dikontruksikan pada bagian bawah agar kokoh dibagain lantai rumah adat Gayo. Melalui filosofi itu juga rumah adat Gayo dibuat tujuh ruang dan disebut juga namanya umah pitu ruang.

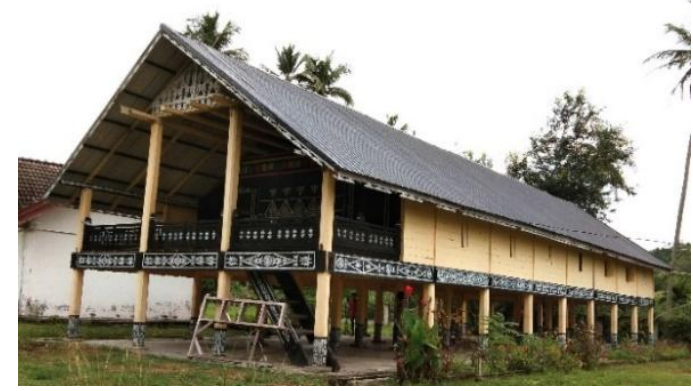

Gambar 2. Rumah adat Gayo Kerajaan Linge (Sumber: Ansar Salihin, 2018)

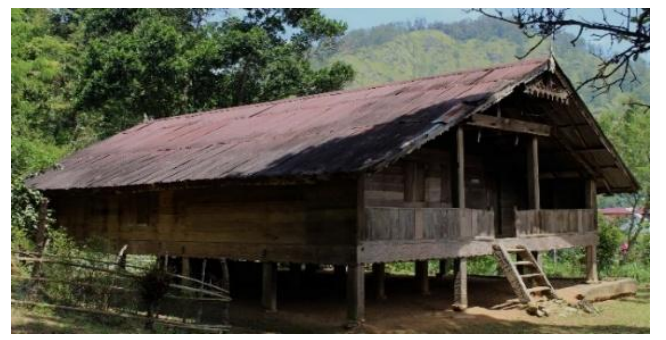

Gambar 3. Rumah adat Gayo Kerajaan Baluntara (Sumber: Ansar Salihin, 2018)

Saat ini ada empat rumah adat Gayo yang terdapat di Aceh Tengah, diantaranya: Rumah adat Gayo kerajaan Linge terletak di kompleks museum umah pitu ruang reje Linge di Buntul Linge, Desa Linge, Kecamatan
Gorga Jurnal Seni Rupa

Volume 08 Nomor 01 Januari-Juni 2019

p-ISSN: 2301-5942 | e-ISSN: 2580-2380

Linge. Tempat ini merupakan pertama kali berdirinya rumah adat Gayo masa raja Bujang Genali. Rumah adat Gayo yang asli sudah terbakar, kemudian dibangun kembali tahun 2002 oleh Pemerintah Kabupaten Aceh Tengah.

Rumah adat Gayo kerajaan Baluntara adalah rumah adat tertua pada saat ini, kurang lebih sudah berumur 200 tahun. Rumah adat Gayo kerajaan Baluntara terletak di pinggir Danau Lut Tawar kampung Toweren Kecamatan Laut Tawar. Komponen rumah adat ini masih asli, begitu juga dengan ukirannya masih asli belum ada perubahan.

Rumah adat Gayo ini dibuat oleh Pemerintah Aceh Tengah pada tahun 2000 tujuannya melestarikan rumah adat Gayo, sehingga di bangun rumah adat sebagai ikon yang difungsikan sebagai museum rumah adat Gayo, oleh karena itu, letaknya berada di kota takengon sebagai ibu kota kabupaten Aceh Tengah. Rumah adat Gayo yang terletak di Taman Ratu Safiatuddin merupakan anjungan atau ikon kabupaten Aceh Tengah di pusat provinsi Aceh. Taman Ratu Safiatuddin adalah taman mini Aceh, semua kabupaten di Aceh memiliki rumah adat di kompleks tersebut. Rumah adat Gayo Aceh Tangah dibangun pada tahun 2004 .

\section{2).Motif Kerawang Gayo}

Kerawang terdiri ari kata "Ker rum Rawang", Ker = daya fikir sedangken Rawang = ramal atau bayangen . Lagu si cecerak wan peri mestike: "Ku atas mupucuk bulet, ku tuyuh mujantan tegep. I dema ku ate, terang wan kekire" (Bentara, 2017: 83).

Artinya: Kerawang terdiri dari kata "Ker dan Rawang”, Ker = daya fikir sedangkan rawang = ramal atau imajinasi. Seperti pepatah dalam falsafah Gayo: "ke atas berpucuk bulat, ke bawah terikat kuat. Di bawa ke hati/perasaan, terang dalam bayangan/imajinasi”.

Kerawang merupakan wujud dari imajinasi spontanitas individu manusianya. Di dalam kata kerawang melibatkan dua interaksi, yakni 1) interaksi perasaan hati dan 2) interaksi alam fikiran. Kedua interaksi tersebut terwujud sebagai simbol imajinasi manusia yang berdaya guna. Berbagai wujud-wujud ini bersumber dari fenomena alam yang dinalari oleh manusianya (Joni, 2017: 38)

Kerawang adalah hiasan untuk memperindah benda, dalam hal ini untuk memperindah rumah adat Gayo, yang dibuat oleh nenek moyang masyarakat Gayo. Motif-motif yang diterapkan pada rumah adat yang 


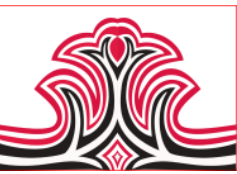

dibuat pada dasarnya berangkat dari alam sekitar mereka.

Kerawang yang bersumber dari kata ker dan rawang adalah imagologi edet, yaitu imajinasi manusianya itu diikat dengan norma adat, yang diwujudkan dengan benda-benda alam yang ada disekitar mereka. Setiap motif itu ker-nya dulu dibawa ke perasaan, kemudian barulah rawang atau diterawang masuk ke dalam imajinasi, maka lahirlah motif berupa bentuk sesuai dengan maknanya yang berhubungan dengan kehidupan masyarakatnya (Wawancara Joni, 12 Agustus 2018)

Berdasarkan beberapa definisi kerawang di atas dapat dipahami bahwa kerawang merupakan hiasan berupa motif-motif atau ragam hias yang ditempatkan pada suatu benda seperti rumah adat Gayo berupa ukiran. Fungsi utamanya adalah sebagai hiasan, setelah melalui proses ker dan rawang (daya fikir dan imajinasi) motif-motif tersebut malahirkan suatu makna filosofi yang berkaitan dengan kehidupan masyarakat. Berikut beberapa ukiran motif kerawang Gayo yang terdapat pada rumah adat Gayo.

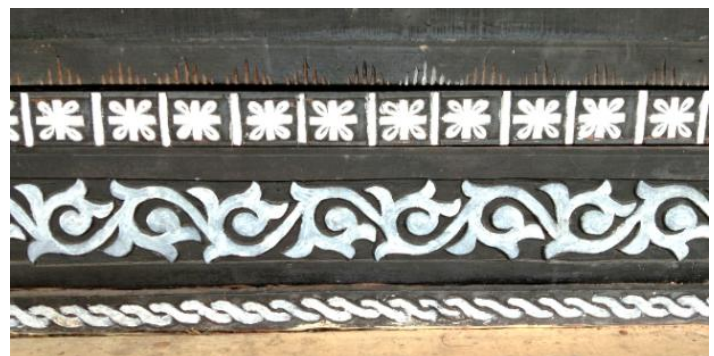

Gambar 4. Motif Ukiran Kerawang GAYO pada Dinding Depan Rumah Adat Gayo Kerajaan Linge

(Sumber: Ansar Salihin, 2018)

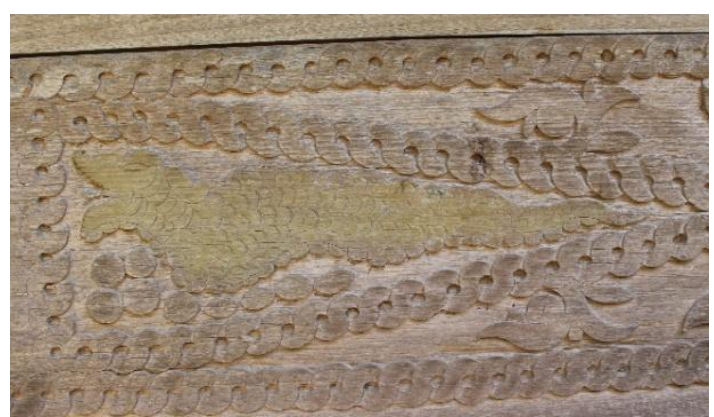

Gambar 5. Motif Ukiran Kerawang Gayo pada Dinding Rumah Adat Gayo Kerajaan Baluntara

(Sumber: Ansar Salihin, 2018)

\section{Pembahasan}

Motif ukiran kerawang Gayo pada rumah adat Gayo terbagi tiga jenis motif, yaitu motif utama, motif pendukung dan motif isian. Motif utama merupakan
Gorga Jurnal Seni Rupa

Volume 08 Nomor 01 Januari-Juni 2019

p-ISSN: 2301-5942 | e-ISSN: 2580-2380

motif inti dari kerawang Gayo yang diterapkan pada rumah adat Gayo, bentuknya bersumber dari alam, hewan dan peristiwa yang terjadi di lingkungan masyarakat Gayo. Motif utama lebih menonjol dan lebih besar dari motif lain, diterapkan beberapa bagian sesuai dengan bentuk artistik rumah adat Gayo.

Kemudian motif pengisi atau motif pendukung merupakan moti-motif ukiran yang mendukung dan menghias motif utama. Motif pengisi pada ukiran rumah adat Gayo berupa motif bunga, bintang, dan bentuk geometris lainnya. Sebagian motif pendukung melekat pada motif utama dan ada juga terpisah dari motif utama atau diletakan diantara motif utama. Motif pendukung sebagian memiliki nama secara bahasa Gayo, sebagian lagi tidak memiliki nama, namun ada bentuk motif ukirannya diterapakan pada rumah adat Gayo. Motif tersebut diantaranya: bungi ni kapas (bunga kapas), bunge ni pertik (Bunga pepaya), bintang (bintang), bintang ulen (bintang bulan), telur naga pada motif naga dan bentuk bunga lainnya yang tidak memiliki nama.

Motif isian pada ukiran rumah adat Gayo merupakan motif-motif penghias motif utama dan motif pendukung dengan tujuan untuk melengkapi motif utama dan pendukung agar tampilannya lebih indah. Motif isian tidak ada nama khusus dalam istilah kerawang Gayo, namun tetap berarti penting dalam penerapan ukiran. Motif isian yang terdapat pada rumah adat Gayo seperti garis sisik pada motif nege (naga), garis sisik pada motif iken (ikan), garis-garis bulu pada motif kurik (iken) dan bentuk garis dan titik yang terdapat pada motif lainnya.

Berikut ini bentuk dan makna filosofi motif utama kerawang Gayo pada Rumah Adat Gayo Aceh Tengah:

\section{1).Motif Emun Berangkat}

Emun berangkat adalah lambang rasa kesetiakawanan dalam kesatuan, dalam peri mestike (pri bahasa) Gayo menyebutkan "beloh sara loloten mewen sara tamunen" artinya kalau pergi ada yang dijemput, kalau tinggal ada yang dijaga. Ini merupakan gambaran kesetiaan masyarakat Gayo dalam masyarakat, kehidupan mereka kalau sudah satu kampung atau satu tempat tinggal itu seperti saudara kandung satu ayah satu ibu (Wawancara: Joni, 12 Agustus 2018).

Motif emun berangkat (awan berarak) adalah motif yang bersumber dari bentuk gerakan awan yang berarak ditiup angin. Filosofi emun berangkat tertuang dalam peri mestike (falsafah/pepatah Gayo) yang artinya pergi satu iringan, tinggal satu kumpulan. 


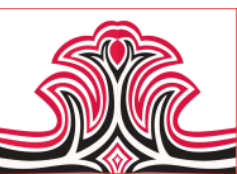

Makna filosofinya adalah kesetiaan, kekompakan dan kesatuan. Pesan ajaran dapat diambil dari motif emun berangkat adalah gambaran kehidupan masyarakat yang kompak, saling menjaga persatuan dan kesatuan.

\section{2).Motif Emun Beriring}

Emun beriring berupa bayangan awan saat dipandang bentuknya seperti beriring. Pepatah adat Gayonya "mususun lagu belo, rempak lagu re" artinya bersusun seperti daun sirih, sejajar seperti sisir. Maknanya berkumpul secara bersama dan tidak bercerai-berai dalam kehidupan masayarakat (Wawancara: Bentara, 12 Agustus 2018).

Motif emun beriring (awan berbaris) merupakan motif yang bersumber dari gulungan awan yang berbaris. Maknanya dalam kehidupan bermasyarakat harus menjaga persatuan dan kekompakan, kemudian kesetaraan dalam masyarakat tidak ada yang lebih tinggi dan tidak ada yang lebih rendah, saling menghormati dan saling menghargai, artinya masyarakat itu sejajar dalam kedudukannya.

\section{3).Motif Emun Berkune}

Emun berkune secara bahasa tidak dapat diartikan ke dalam bahasa Inonesia. Kalau kita memandang kumpulan awan di langit dicelah-celahnya kelihatan langit, maka pemandangan kita antara melihat awan dan langit atau melihat awan tembus ke langit. Munculah suatu pertanyaan "mukune emunno engon emun temus ku langit" artinya kenapa emun itu, lihat awan tembus ke langit. Masyarakat Gayo menamakn itu emun berkune, filosofinya "bulet lagu umut, tirus lagu gelas" maknanya melambangkan demokrasi dalam mencari kebenaran untuk mengambil keputusan dan dilaksanakan dengan rasa tanggungjawab (Wawancara: Joni, 12 Agustus 2018).

Falsafah motif emun berkune "bulat seperti batang pisang, lurus seperti gagang pancing”. Batang pisang berbentuk lingkaran bulat mulai dari pangkalnya besar kemudian semakin ke atas semakin kecil, kemudian gagang pancing pangkalnya besar lalu semakin keujung semakin kecil. Maknanya adalah dalam menyelesaikan masalah harus memiliki kesepakatan yang sama, menghasilkan suatu keputusan bersama yang bulat.

\section{4).Motif Emun Mupesir}

Emun mupesir berupa gambaran awan berpencar dari sedikit kemudian bertambah banyak, ini kiasan dari penambahan penduduk dengan perluasan wialayah baru. Seperti falsafah Gayo "Ari kerna sempit mungenaken lues, ari kerna nyanya mengenaken temas" maknanya adalah kalau suatu tempat sudah
Gorga Jurnal Seni Rupa

Volume 08 Nomor 01 Januari-Juni 2019

p-ISSN: 2301-5942 | e-ISSN: 2580-2380

mulai sempit karena banyaknya penduduk maka harus diperluas tempat tersebut, kemudian kalau kehidupan susah maka harus cari kehidupan baru untuk hidup yang lebih layak. Diumpamakan kehidupan dalam suatu keluarga, apabila ada anak yang sudah menikah dan sudah memiliki anak lagi, maka keluarga baru tersebut akan pindah membuat rumah baru (Wawancara: Bentara, 12 Agustus 2018).

Motif emun mupesir (awan berpencar) adalah kumpulan awan yang berpencar atau pecah akibat dihembus angin. Motif emun mupesir menggambarkan bentuk awan yang berpencar, bentuk motifnya hampir sama dengan motif emun berkune, atau pecahan dan pengembangan dari motif emun berkune. Filosofi motif emun berkune "dari karena sempit berkeinginan memperluar wilayah, dari karena susah berkeinginan hidup sejahtera" makna yang dapat diambil dari falsafah ini adalah dalam hidup jangan bergantung kepada keadaan, manusia harus berfikir untuk mencari kehidupan lebih baik. Kalau wilayah sudah sudah sempit kerena banyaknya penduduk, jangan dipaksakan bertahan cari tempat baru untuk berusaha. Kalau kehidupan miskin jangan hanya pasrah terhadap kemiskinan, cari pekerjaan untuk kehidupan lebih layak.

\section{5).Motif Emun Mutumpuk}

Emun mutumpuk adalah motif gambaran awan dipandang seperti berkumpul yang memiliki makna seperti majelis musyawarah membahas masalah penting. Peri mestike Gayo menyebutkan "Ratip musara anguk, nyawa musara peluk" maknanya bertanggungjawab dalam suatu keputusan musyawarah dengan malaksanakanya secara bersama. Kalau ada suatu permasalahan, kemudian dimusyawarahkan secara bersama untuk menghasilakan suatu keputusan, maka hasil keputusan tersebut menjadi keputusan secara adat wajib untuk dijalankan oleh masyarakat Gayo (Wawancara: Bentara, 12 Agustus 2018).

Motif emun mutumpuk (awan berkumpul) merupakan gambaran awan yang berkumpul di langit atau di atas bukit setelah berarak dari tempat yang lebih rendah. Seperti filosofi "Ratip musara anguk, nyawa musara peluk" artinya ratib (gerakan dalam berzikir) harus satu angguk, nyawa harus satu kumpulan. Maknanya adalah suatu keputusan bersama wajib diikuti dan ditaati oleh semua masyarakat, tidak ada lagi aturan lainnya selain keputusan bersama. Pesan ajarannya adalah perlunya sebuah perkumpulan untuk bermusyawarah dalam memutusakan suatu persoalan, hasil keputusan ini harus dijalankan secara bersama. 


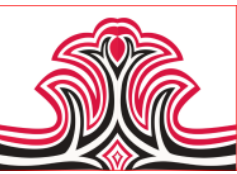

\section{6).Motif Puter Tali}

Puter tali adalah gambaran seperti tali yang dipilin yang pergunakan dalam mengikat suatu benda. Biasaya masyarakat Gayo menggunakan puter tali ini untuk mengikat pagar kebun agar tidak dimasuki oleh hewan, atau mengikat peruweren atau kawasan untuk kandang hewan kerbau atau sapi, agar hewan-hewan tersebut tidak keluar. Untuk mengikat pagar tersebut membutuhkan tali yang kuat agar tidak putus, maka masyarakat membuatnya dengan cara dipilin dua atau tiga tali. Falsafah masyarakat Gayo mengatakan "keramat mupakat, behu berdedeli" maknanya apapun masalah selesai dengan cara musyawarah dan sepadan dalam berkumpul untuk menghasilakn suatu keputusan (Bentara, 12 Agustus 2018).

Motif puter tali (putar tali/pilin berganda) merupakan motif bersumber dari tali yang dipilin secara ganda. Pembuatan tali dipilin secara ganda bertujuan untuk memperkuat tali dalam mengikat suatu benda. Filosofi motif puter tali "bersama dalam musyawarah, burkumpul ramai-ramai”. Maknanya adalah persatuan dan kesatuan, saling peduli antara sesama. Pesan ajaran yang dapat diambil dari motif puter tali adalah, rasa peduli dan kebersamaan harus seperti pilin berganda, bersama akan lebih kuat dan tidak mudah untuk dipecah belahkan.

\section{7).Motif Pucuk Rebung}

Rebung adalah tumbuhan yang hidup di tanah Gayo, cikal bakal tumbuhnya bambu. Rebung banyak manfaat dalam masyarakat Gayo, jika ada pesta rebung digunakan untuk jantar pengat (sayur kering), hampir setiap pesta ada sayur rebung ini. Motif pucuk rebung bentuknya segitiga, dalam masyarakat Gayo memiliki makna kesuburan dan generasi muda yang harus diperhatikan. Harapan ini tertuang dalam pepapatah Gayo "pantas berule, lemem bertona" yaitu sepapah, sepupuh, senasip sepenanggungan, saling mengingatkan antara yang tua dengan yang muda. (Wawancara: Zainal, 3 Januari 2019).

Motif pucuk rebung merupakan motif yang berasal dari gambaran rebung atau tunas bambu yang baru tumbuh. Motif pucuk rebung melambangkan proses pembinaan dan pendidikan generasi muda di Gayo dalam membangun bangsa. Seperti filosofi "cepat berjalan didahulukan, lambat berjalan didampingi". Maknanya adalah orang tua harus menuntun anak muda dalam bermasyarakat, agar kelak ia dapat membangun negeri tersebut.

\section{8).Motif Terkukur}

Tekukur merupakan lambang mengambil keputusan, seperti peri mestike Gayo menyebutkan "inget
Gorga Jurnal Seni Rupa

Volume 08 Nomor 01 Januari-Juni 2019

p-ISSN: 2301-5942 | e-ISSN: 2580-2380

sebelem kona jimet tengah ara, sejangkal ku arap sedepa kukuduk, ike lungi enti tir i telan, ike pit enti tir $i$ loahen" maknanya setiap mengambil keputusan harus mempertimbangkan dengan penuh arif dan bijaksana, setiap melakukan sesuatu harus difikirkan terlebih dahulu tentang baik dan buruknya (Wawncara: Joni, 12 Agustus 2018).

Motif tekukur (pengukuran) merupakan motif geometris berbentuk empat bulatan dibatasi dua garis horizontal dan vertikal. Motif tekukur merupakan lambang keadilan dalam mengambil suatu keputusan dalam bermusyawarah masyarakat Gayo. Pesan ajaran yang dapat diambil dari motif tekukur adalah dalam mengambil suatu keputusan harus teliti, penuh pertimbangan dan bersikap adil secara hukum. Setiap keputusan akan menentukan nasib orang, baik personal maupun kelompok masyarakat.

\section{9).Motif Mata Ni Lo}

Mata ni lo merupakan lambang sumber kehidupan untuk segala makhluk, dalam peri mestike Gayo menyebutkan "mupestak pejer, mubiner mata ni lao" maknanya adalah syukur atas nikmat sabar atas cobaan yang dihadapi di dunia. Mengekspresikan hubungan manusia dengan sang pencipta dan hubungan sesama makhluk (Wawancara: Joni, 12 Agustus 2018).

Motif mata ni lo (matahari) adalah motif yang bersumber dari bentuk cahaya matahari. Berdasarkan pendapat di atas motif mata ni lo merupakan lambang sumber kehidupan. Matahari telah memberikan kehidupan, maka manusia harus tetap bersyukur atas nikmat itu dan tetap bersabar apabila menimpa musibah. Hubungan dengan tuhan selalu dijaga dengan melaksanakan perintahnya, tidak lupa juga berbaik hati dengan semua makhluk di dunia. Pesan yang dapat diambil dari motif mata ni lo adalah matahari sebagai sumber kehidupan, mengajarkan kepada manusia selalu bersinar menebarkan kebaikan kepada siapa saja mahkluk yang ada di bumi ini.

\section{0).Motif Sarak Opat}

Sarak opat merupakan gabungan unsur jabatan raja, dalam falsafah Gayo menyebutkan "reje musuket sifet, imem muperlu sunet, petue musisdik sasat, rakyat genap mupakat" artinya raja memiliki sifat suket yaitu adil dan bijaksana, iman melaksanakan syariat, petue/tokoh mempunyia sifat sidik dan siasat, rakyat berkumpul bermusyawarah. Inilah sistem kepemimpinan dan musyawarah dalam masyarakat Gayo (Wawancara: Swito, 20 Juni 2018). 
Sarak adalah unsur pimpinan di Gayo, sementara opat adalah angka empat, jadi sarak opat adalah perkumpulan unsur empat pimpinan yaitu reje (raja) imem (iman), petue (tokoh masyarakat) dan rakyat (perwakilan masyarakat). Empat unsur pimpinan dalam memutusakan suatu permasalahan dalam musyawarah yang terdiri raja harus bersifat adil dalam mengambil keputusan, tokoh masyarakat harus memiliki sifat menyelidiki dan mensiasati tentang kehidupan masyarakat, imam memperhatikan dan melaksanakan syariat dalam musyawarah, rakyat sepakat berkumpul untuk menyetujui hasil musyawarah. Pesan ajaran yang dapat diambil dari motif sarak opat ini adalah adanya kolaborasi empat unsur pimpinan dengan latar keahlian dan pandangan yang berbeda untuk memutuskan suatu permasalahan dalam bermusyawarah.

\section{1).Motif Nege}

Nege dipercaya oleh masyarakat Gayo sebagai penjaga pegunungan, apabila terjadi banjir bandang, masyarakat beranggapan bahwa naga marah disebabkan manusia merusak alam. Benar dak tidaknya tidak dapat dibuktikan hanya cerita-cerita turun-temurun saja. Makna yang dapat diambil dari cerita itu adalah naga merupakan pelindung alam yang memiliki kekuatan. Motif naga hanya terdapat di rumah adat Baluntara tidak ada di rumaha adat Gayo yang lain, karena alasan syariat Islam motif nege sudah mulai dihilangkan dan tidak masuk lagi ke dalam motif kerawang. (Wawancara: Swito, 20 Juni 2018).

Motif nege (naga) adalah motif ilustrasi gambaran masyarakat Gayo terhadap hewan naga. Motif nege memiliki makna penjaga alam, makhluk yang memiliki kekuatan dan kekuasaan. Meskipun wujud hewan ini tidak pernah dilihat oleh manusia, namun ada nilai dan pesan yang dapat diambil dari motif nege, yaitu manusia semestinya menjaga alam dengan baik, tidak boleh merusak alam, menebang pohon di hutan dan sebagainya yang dapat mengakibatkan terjadinya bencana alam.

\section{2).Motif Iken}

Motif iken secara sejarah reje Linge memiliki arti penting, karena pada masa pernikahan reje Genali ikan ini dijadikan "penanun petemun" artinya yang mengantarkan mahar melewati lautan. Ikan juga dipercaya pada zaman dahulu pengawal raja yang setia di laut. Hal ini boleh dipercaya boleh tidak, inilah ceritanya secara turun temurun. Nilai yang dapat diambil dari motif iken ini adalah kesetiaan seorang pengawal kepada seorang raja. Motif iken sama halnya
Gorga Jurnal Seni Rupa

Volume 08 Nomor 01 Januari-Juni 2019

p-ISSN: 2301-5942 | e-ISSN: 2580-2380

juga seperti motif nege sudah dihilangkan dengan alasan syariat Islam, namun pada rumah adat Gayo Kerajaan Baluntara tetap dipertahankan (Wawancara, Swito, 20 Juni 2018).

Motif iken (ikan) merupakan motif bersumber dari bentuk ikan. Motif iken juga hanya terdapat pada rumah adat kerajaan Baluntara, tidak ada pada rumah adat Gayo lainnya. Pesan ajaran yang dapat diambil dari motif ikan adalah kesetian ikan dalam mengawal raja dalam perjalanan di laut untuk menyebrang ke suatu negeri, ikan berani menjamin keselamatan raja dalam perjalanan di laut. Ini merupakan gambaran kesetiaan pengawal kepada pimpinan dalam berpergian, seorang pengawal harus berani menjamin keselamatan pemimpinnya, tidak boleh berkhianat terhadap pemimpin, seorang pengawal harus siap memepertarukan nyawa demi keselamatan pemimpin.

\section{3).Motif Kurik}

Ayam hubungannya dengan kehidupan manusia, disamping pertanian usaha masyarakat Gayo juga memelihara unggas seperti ayam. Maka motif kurik ini erat kaitannya dengan kehidupan manusia, hewan yang dekat dengan manusia. Dalam bahasa Gayo maka ada istialah "tuk kurik" artinya ayam berkokok, maksudnya itu menunjukan waktu menjelang subuh. Ibaratnya ayam ini yang membangunkan manusia untuk menunaikan shalat subuh (Wawancara: Syeh Syamsudin, 29 Desember 2016).

Motif kurik (ayam) adalah motif bersumber dari hewan peliharaan manusia yaitu ayam. Hewan ini adalah salah satu hewan yang dekat dengan manusia. Nilai filosofi yang dapat diambil menjadi pesan ajaran dari motif kurik adalah kedekatan ayam dengan kehidupan manusia, menjelang subuh ayam membangunkan manusia. Ayam menjadi hewan yang mulia karena memberikan manfaat untuk manusia. Oleh karena itulah masyarakat zaman dahulu menerapkannya pada ukiran rumah adat Gayo. 


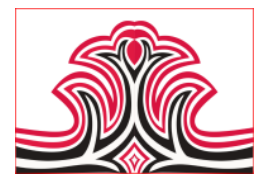

Tabel 1. Motif ukiran kerawang Gayo pada rumah adat Gayo

\begin{tabular}{|c|c|c|c|c|}
\hline No & Bentuk Motif & $\begin{array}{l}\text { Nama } \\
\text { Motif }\end{array}$ & $\begin{array}{c}\text { Peri } \\
\text { Mestike } \\
\text { (Filosoof } \\
\text { i) }\end{array}$ & Makna \\
\hline 1 & त्रे & $\begin{array}{l}\text { Emun } \\
\text { Berangkat } \\
\text { (Awan } \\
\text { Berarak) }\end{array}$ & $\begin{array}{l}\text { beloh } \\
\text { sara } \\
\text { loloten } \\
\text { mewen } \\
\text { sara } \\
\text { tamunen }\end{array}$ & $\begin{array}{l}\text { Kesetiaan } \\
\text { dan } \\
\text { kekompa } \\
\text { kan }\end{array}$ \\
\hline 2 & ves. & $\begin{array}{l}\text { Emun } \\
\text { Beriring } \\
\text { (Awan } \\
\text { Berbaris) }\end{array}$ & $\begin{array}{l}\text { mususun } \\
\text { lagu belo } \\
\text { rempak } \\
\text { lagu re }\end{array}$ & $\begin{array}{l}\text { Kebersa } \\
\text { maan, } \\
\text { persatuan } \\
\text { dan } \\
\text { kesatuan }\end{array}$ \\
\hline 3 & & $\begin{array}{l}\text { Emun } \\
\text { Berkune } \\
\text { (Awan } \\
\text { Bercabang) }\end{array}$ & $\begin{array}{l}\text { bulet } \\
\text { lagu } \\
\text { umut, } \\
\text { tirus lagu } \\
\text { gelas }\end{array}$ & $\begin{array}{l}\text { Demokra } \\
\text { si, } \\
\text { bertangg } \\
\text { ungjawab } \\
\text { dan } \\
\text { putunjuk } \\
\text { arah }\end{array}$ \\
\hline 4 & & $\begin{array}{l}\text { Emun } \\
\text { Mupesir } \\
\text { (Awan } \\
\text { Berpencar) }\end{array}$ & $\begin{array}{l}\text { Ari kerna } \\
\text { sempit } \\
\text { mungena } \\
\text { ken lues, } \\
\text { ari kerna } \\
\text { nyanya } \\
\text { mengena } \\
\text { ken } \\
\text { temas }\end{array}$ & $\begin{array}{l}\text { Perantaua } \\
\mathrm{n} \text {, } \\
\text { berusaha } \\
\text { memperb } \\
\text { aiki } \\
\text { hidup }\end{array}$ \\
\hline 5 & & $\begin{array}{l}\text { Emun } \\
\text { Mutumpuk } \\
\text { (Awan } \\
\text { Berkumpul) }\end{array}$ & $\begin{array}{l}\text { Ratip } \\
\text { musara } \\
\text { anguk, } \\
\text { nyawa } \\
\text { musara } \\
\text { peluk } \\
\end{array}$ & $\begin{array}{l}\text { Berkump } \\
\text { ul, } \\
\text { bermusya } \\
\text { warah }\end{array}$ \\
\hline 6 & & $\begin{array}{l}\text { Puter Tali } \\
\text { (Pilin } \\
\text { Berganda) }\end{array}$ & $\begin{array}{l}\text { keramat } \\
\text { mupakat, } \\
\text { behu } \\
\text { berdedeli }\end{array}$ & $\begin{array}{l}\text { Bersatu } \\
\text { untuk } \\
\text { kekuatan }\end{array}$ \\
\hline 7 & & $\begin{array}{l}\text { Pucuk } \\
\text { Rebun } \\
\text { (Pucuk } \\
\text { Rebung) }\end{array}$ & $\begin{array}{l}\text { pantas } \\
\text { berule, } \\
\text { lemem } \\
\text { bertona }\end{array}$ & $\begin{array}{l}\text { Pendidik } \\
\text { an, } \\
\text { generasi } \\
\text { muda }\end{array}$ \\
\hline 8 & & $\begin{array}{l}\text { Tekukur } \\
\text { Pengkuran }\end{array}$ & $\begin{array}{l}\text { inget } \\
\text { sebelem } \\
\text { kona } \\
\text { jimet } \\
\text { tengah } \\
\text { ara, } \\
\text { sejangkal } \\
\text { ku arap } \\
\text { sedepa } \\
\text { kukuduk, } \\
\text { ike lungi } \\
\text { enti tir } i \\
\text { telan, ike } \\
\text { pit enti } \\
\text { tir } i \\
\text { loahen }\end{array}$ & $\begin{array}{l}\text { Adil dan } \\
\text { bijaksana } \\
\text { dalam } \\
\text { mengamb } \\
\text { il } \\
\text { keputusa } \\
\mathrm{n}\end{array}$ \\
\hline 9 & & $\begin{array}{l}\text { Mata Ni Lo } \\
\text { (Matahari }\end{array}$ & $\begin{array}{l}\text { mupestak } \\
\text { pejer, } \\
\text { mubiner } \\
\text { mata ni } \\
\text { lao }\end{array}$ & $\begin{array}{l}\text { Sumber } \\
\text { kehidupa } \\
\text { n, syukur } \\
\text { atas } \\
\text { nikmat, } \\
\text { sabar atas } \\
\text { cobaan }\end{array}$ \\
\hline 10 & & $\begin{array}{l}\text { Sarak Opat } \\
\text { (Sarak } \\
\text { Empat) }\end{array}$ & $\begin{array}{l}\text { reje } \\
\text { musuket } \\
\text { sifet, } \\
\text { imem } \\
\text { muperlu }\end{array}$ & $\begin{array}{l}\text { Empat } \\
\text { unsur } \\
\text { pimpinan } \\
\text { dalam } \\
\text { musyawa }\end{array}$ \\
\hline
\end{tabular}

Gorga Jurnal Seni Rupa

Volume 08 Nomor 01 Januari-Juni 2019

p-ISSN: 2301-5942 | e-ISSN: 2580-2380

\begin{tabular}{|l|l|l|l|l|}
\hline & & & $\begin{array}{l}\text { sunet, } \\
\text { petue } \\
\text { musisdik } \\
\text { sasat, } \\
\text { rakyat } \\
\text { genap } \\
\text { mupakat }\end{array}$ & rah \\
\hline 11 & & - & $\begin{array}{l}\text { Kekuatan } \\
\text { dan } \\
\text { kekuasaa } \\
\text { n }\end{array}$ \\
\hline 12 & Nege & (Naga) & $\begin{array}{l}\text { Kesetiaan } \\
\text { pengawal } \\
\text { raja }\end{array}$ \\
\hline 13 & Iken & - & $\begin{array}{l}\text { Kemuliaa } \\
\text { ndan } \\
\text { kedekata } \\
\text { ndengan } \\
\text { manusia }\end{array}$ \\
\hline
\end{tabular}

\section{KESIMPULA DAN SARAN}

\section{Kesimpulan}

Kerawang merupakan hiasan berupa motif-motif atau ragam hias masyarakat Gayo yang ditempatkan pada suatu benda. Salah satu motif kerawang Gayo terletak pada ukiran rumah adat Gayo di Aceh Tengah. Kerawang merupakan hasil karya masyarakat Gayo diciptakan melalui proses ker dan rawang (perasaan dan imajinasi) dirasakan dengan hati dikembangkan dengan pemikiran. Melalui proses itu melahirkan bentuk motif yang memiliki peri mestike atau falsafah dan ajaran dalam kehidupan masyarakat Gayo.

Motif ukiran kerawang Gayo pada rumah adat Gayo di Aceh Tengah diantaranya emun berangkat (awan berarak), emun beriring (awan berbaris) emun berkune (awan bercabang) emun mupesir (awan berpencar) eтип mutumpuk (awan berkumpul) puter tali (pilin berganda) pucuk rebun (pucuk rebung) tekukur (pengkuran) mata ni lo (matahari) sarak opat (sarak empat) nege (naga) iken (ikan) dan kurik (ayam). Tiga motif diantaranya penggambaran hewan motif nege (naga) iken (ikan) dan kurik (ayam) hanya terdapat pada rumah adat Gayo kerajaan Baluntara, sedangkan pada rumah adat Gayo lainnya tidak diterapkan lagi, dengan alasan syariat Islam yang berlaku di Aceh Tengah.

Motif ukiran tersebut memiliki beberapa sumber ide dalam pembuatannya yang berangkat dari peristiwa dan lingkungan masyarakatnya. Nilai-nilai yang terkandung setiap bentuk motif memiliki nilai filosofi dan makna yang menjadi tuntunan dalam hidup masyarakat Gayo. Melalui penelitian ini mengkaji estetika bentuk dan makna filosofi motif kerawang Gayo pada rumah adat Gayo, nilai dan pesan ajaran tersebut dapat menjadi tuntunan dalam masyarakat di masa sekarang dan masa yang akan datang. 


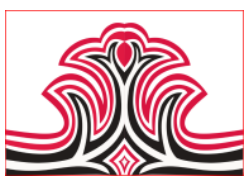

2.Saran

Hasil penelitian ini diharapankan dapat menjadi acuan untuk penelitian selanjutnya lebih dalam mengkaji tentang motif ukiran kerawang pada rumah adat Gayo atau penelitian sejenisnya. Kemudian dapat menjadi dokumen akademik dipergunakan sebagai referensi ilmiah baik untuk peneliti, dosen, mahasiswa dan kalangan akademik yang membutuhkan. Memperhatikan kondisi masyarakat Gayo saat ini, sudah mulai tidak mengenal nama-nama motif kerawang Gayo dan sama sekali tidak mengetahui makna-makna yang terkandung dalam motif tersebut, maka diharapkan hasil penelitian ini dapat dipublikasikan dan disosialisasikan kepada masyarakat umum melalui pemerintah daerah.

\section{DAFTAR RUJUKAN}

Ibrahim, Mahmud. (2007). Mujahid Dataran Tinggi Gayo. Takengon: Yayasan Maqamamahmuda.

Ibrahim, Mahmud., \& Hakim, A. R. Aman Pinan. (2002). Syariat dan Adat Istiadat Takengon: Yayasan Maqamam Mahmuda.

Irfani, Sylviana Mirahayu. (2015). Kajian Arsitektur Tradisional Sebagai Acuan Desain Rumah Tinggal Kontemporer (Studi Kasus: Arsitektur Vernakular Gayo Lut Di Kota Takengen). Tesis. Medan: Universtas Sumatera Utara.

Joni., Linge, Bentara., \& Luttawar, Ibnu Hajar. at al. (2017). Kerawang Gayo. Tangerang: Mahara Publishing.

Junaedi, Eni. (2016). Estetik Jalinan Subjek, Objek dan Nilai. Yogyakarta: Artciv

Linge, Bentara. (2017). Edet Ari Merhum Ukum Ari Syah Kuala. Tangerang: Mahara Publishing.

Rohendi Rohini, Tjetjep. (2011). Metodologi Penelitian Seni. Semarang: Cipta Prima Nusantara.

Sony Kartika, Dharsono. (2004). Seni Rupa Modern. Bandung: Rekayasa Sains.

Sony Kartika, Dharsono. (2016). Kreasi Artistik Perjumpaan Tradsi Modern dalam Paradigma Kekaryaan Seni. Karangenyar: Citra Sain.

Suryajaya, Martin. (2016). Sejarah Estetika. Jakarta: Gang Kabel.

Tamraz., \& Ibrahim, Mahmud. et al. (1998). Seni Rupa Aceh. Aceh: PEMDA NAD.

Abdussalam, 54 tahun, Kepala Desa, Budayawan, Desa Linge Aceh Tengah, 2 Januari 2017.

Bentara Linge, 52 tahun, Petani, Budayawan/Anggota Majelis Adat Gayo, Dusun Lintang Kecamatan Stabat Kabupaten Langkat Sumatera Utara, 12 Agustus 2018.

Dr. Joni, M.Pd. B.I, 47 tahun, Dosen, Pengkaji Adat Budaya Gayo/Anggota Majelis Adat Gayo, Desa Pinangan Takengon Aceh Tengah, 12 Agustus 2018.
Gorga Jurnal Seni Rupa

Volume 08 Nomor 01 Januari-Juni 2019

p-ISSN: 2301-5942 | e-ISSN: 2580-2380

Suwito, 38 tahun, Pengrajin Ukiran Kerawang Gayo, Desa Kung Kecamatan Pegasing Kabupaten Aceh Tengah, 4 Februari 2018.

Syeh Syamsuddin, 58 tahun, Petani, Keturunan Reje Baluntara Generasi ke-4, Desa Toweren Kecamatan Lut Tawar Kabupaten Aceh Tengah, 29 Desember 2016.

Zainal Abidin, M.Pd, 43 tahun, Guru Kriya dan Seni Rupa, Seniman lukis dan pengukir Kerawang Gayo, 3 Januari 2019 